\title{
ANALISA KEGAGALAN TRANSFORMATOR TENAGA BERDASARKAN FMEA (FAILURE MODE AND EFFECT ANALYSIS) SEBAGAI DASAR PERHITUNGAN PENILAIAN KONDISI (SCORING) TRANSFORMATOR TENAGA (STUDI KASUS TRAFO GI SEGOROMADU GRESIK)
}

\author{
Miqdarurridlo (10632007) \\ Jurusan Teknik Elektro -Universitas Muhammadiyah Gresik \\ miqdarurridlo91@gmail.com \\ Jl. Sumatra No.101 Gresik, 61121 Jawa Timur, Indonesia
}

\begin{abstract}
Abstrak
Transformator tenaga merupakan salah satu alat yang terpenting dalam sistem transmisi kelistrikan oleh karena itu diperlukan pemeliharaan dengan cara mengetahui nilai kondisi transformator secara menyeluruh. Namun, belum ada metoda yang secara terperinci dan tepat mengetahui kondisi transformator daya melalui seluruh gabungan data uji yang tersedia. Permasalahan ini menyebabkan tingkat kesimpulan yang berbeda.

Untuk menentukan tingkat unjuk kerja trafo digunakan metode penilaian kondisi (scoring). Penilaian dilakukan dengan cara menganalisa kegagalan transformator dengan berdasarkan FMEA (Failure Mode and Effect Analysis). FMEA merupakan suatu cara untuk menganalisa penyebab/model kegagalan (failure modes) yang dapat terjadi pada suatu sistem yang selanjutnya dapat digunakan sebagai dasar untuk menentukan komponen komponen yang akan diperiksa dan dipelihara. Dalam hal ini dicari mode kegagalan dengan membagi menjadi beberapa subsistem, setelah itu ditentukan parameter apa yang berpengaruh dalam menyebabkan kegagalan. Selanjutnya dilakukan penentuan nilai batas untuk menentukan level kondisi berdasarkan standar yang telah ditetapkan.. Metode ini diterapkan pada penilaian kondisi Transformator Tenaga yang terpasang di GI Segoromadu Gresik.

Dari hasil analisa melalui Inspeksi Level 1,Level 2, maupun Level 3, secara umum Transformator Tenaga di GI segoromadu telah mengalami penurunan kondisi terutama pada Trafo 1 dan Trafo 3 Hasilnya adalah didapatkan hasil scoring yaitu: Trafo $1=5,88$, Trafo $2=8,73$, Trafo $3=4,83$.
\end{abstract}

Kata kunci : Transformator Tenaga, analisa kegagalan transformator, FMEA, penilaian kondisi,

\section{PENDAHULUAN}

\subsection{Latar Belakang}

Kebutuhan masyarakat akan tersedianya tenaga listrik yang reliable (handal) dan memiliki availability (ketersediaan) tinggi adalah wajib hukumnya, salah satu faktor yang mempengaruhi tercapainya target tersebut yaitu performa transformator tenaga yang merupakan salah satu peralatan tunggal yang memiliki nilai aset paling tinggi, terdiri dari hampir $60 \%$ dari total investasi serta merupakan peralatan paling penting dalam penyaluran energy. Untuk meningkatkan performa transformator tenaga perlu dilakukan analisis terhadap resiko kegagalan tranformator, dibutuhkan antisipasi dengan pemantauan dan pemeliharaan kondisi transformator, serta suatu analisa yang bisa menyajikan informasi mengenai diagnosis kondisi transformator.

Banyak metode untuk penilaian kondisi transformator, namun belum ada metoda yang secara terperinci dan tepat mengetahui kondisi transformator daya melalui seluruh gabungan data uji yang tersedia. Permasalahan ini menyebabkan tingkat kesimpulan yang berbeda, sesuai kebutuhan pengujian, atau penilaian yang tidak menyeluruh terhadap kondisi kesehatan 
transformator. Diagnosa kondisi transformator menggunakan metoda scoring transformer ini bertujuan mengukur kondisi transformator secara menyeluruh berdasarkan dari berbagai hasil pengujian dan kriteria kondisi yang terkait dengan faktor-faktor degradasi jangka panjang yang secara kumulatif berpengaruh pada masa hidup operasi transformator, diharapkan gangguan yang mungkin terjadi dapat diidentifikasi pada tahap awal sehingga dapat dilakukan langkah-langkah preventif untuk mencegah terjadinya gangguan yang berakibat pada kegagalan trafo serta dapat mencegah atau membatasi kerusakan transformator tenaga, sehingga mencegah putusnya suplai energi listrik ke konsumen.

Studi diambil dari trafo-trafo yang terpasang di GI Segoromadu yaitu Trafo 1 150/70KV 50MVA, Trafo 2 150/20KV 60MVA dan Trafo 3 150/20KV 60MVA.

\subsection{Rumusan Masalah}

1. Bagaimana menganalisa kegagalan transformator tenaga di GI segoromadu dengan menggunakan FMEA?

2. Bagaimana menentukan score atau nilai kondisi transformator tenaga di GI segoromadu?

\subsection{Tujuan Penelitian}

1. Menganalisa kegagalan transformator tenaga di GI segoromadu Gresik dengan menggunakan FMEA.

2. Menentukan score atau penilaian kondisi transformator tenaga di GI segoromadu.

\section{TINJAUAN PUSTAKA}

\subsection{Teori Kegagalan Isolasi}

Kegagalan isolasi disebabkan beberapa sebab, antara lain isolasi tersebut sudah lama terpakai, berkurangnya kekuatan dielektrik dan karena isolasi tersebut dikenakan tegangan lebih[2]. Pada dasarnya tegangan pada isolasi merupakan suatu tarikan atau tekanan (strees) yang harus dilawan oleh gaya dalam isolasi itu sendiri agar isolasi tidak gagal.
Isolasi berfungsi untuk memisahkan bagian-bagian yang mempunyai beda tegangan agar supaya diantara bagian-bagian tersebut tidak terjadi lompatan listrik (flash-over) atau percikan (spark-over). Kegagalan isolasi pada peralatan tegangan tinggi yang terjadi pada saat peralatan sedang beroperasi bisa menyebabkan kerusakan alat sehingga continuitas sistem menjadi terganggu.

Kegagalan Isolasi bisa terjadi pada:

\section{Bahan Isolasi Padat}

Mekanisme kegagalan pada bahan isolasi padat meliputi kegagalan asasi (intrinsik), elektro mekanik, streamer, thermal dan kegagalan erosi.. Mekanisme kegagalan bahan isolasi padat terdiri dari beberapa jenis sesuai fungsi waktu penerapan tegangannya (Gambar 1).

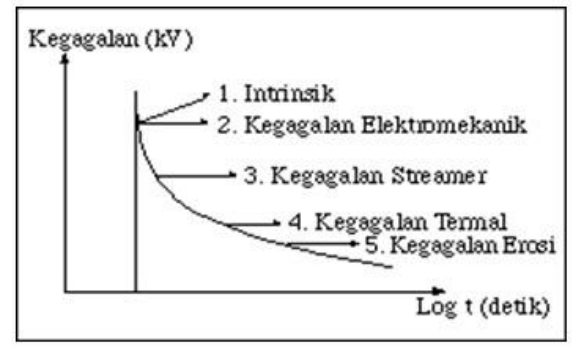

Gambar 1: Grafik Kegagalan Isolasi.

2. Isolasi Zat Cair

Jika suatu tegangan dikenakan terhadap dua elektroda yang dicelupkan kedalam cairan (isolasi) maka terlihat adanya konduksi arus yang kecil. Jika tegangan dinaikkan secara kontinyu maka pada titik kritis tertentu akan terjadi lucutan diantara kedua elektroda.

3. Campuran Zat Cair-Padat

Kegagalan isolasi cair-padat (isolasi kertas dicelup dalam minyak) biasanya disebabkan oleh pemburukan. Pemburukan yang dapat menyebabkan kegagalan isolasi cair-padat adalah pemburukan karena pelepasan dalam (internal discharge) dan pemburukan elektrokimiawi.

\subsection{Transformator Tenaga}

Transformator Tenaga merupakan peralatan statis dimana rangkaian magnetik dan belitan yang terdiri dari 2 atau lebih belitan, secara 
induksi elektromagnetik, mentransformasikan daya (arus dan tegangan) sistem AC ke sistem arus dan tegangan lain pada frekuensi yang sama (IEC 60076 -1 tahun 2011)[8]. Trafo menggunakan prinsip elektromagnetik yaitu hukum hukum ampere dan induksi faraday, dimana perubahan arus atau medan listrik dapat membangkitkan medan magnet dan perubahan medan magnet / fluks medan magnet dapat membangkitkan tegangan induksi (Pamudji, 2014:1). Arus AC yang mengalir pada belitan primer membangkitkan flux magnet yang mengalir melalui inti besi yang terdapat diantara dua belitan, flux magnet tersebut menginduksi belitan sekunder sehingga pada ujung belitan sekunder akan terdapat beda potensial / tegangan induksi.(Gambar 2).

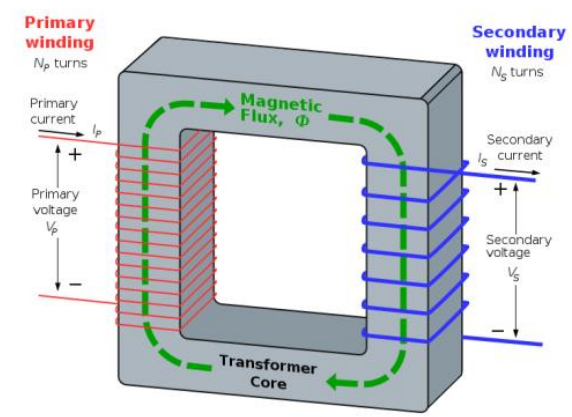

Gambar 2 Prinsip kerja transformator

\subsection{Bagian Transformator}

a. Electromagnetic Circuit (Inti besi).

Inti besi digunakan sebagai media jalannya flux yang timbul akibat induksi arus bolak balik pada kumparan yang mengelilingi inti besi sehingga dapat menginduksi kembali ke kumparan yang lain. Dibentuk dari lempengan - lempengan besi tipis berisolasi yang di susun sedemikian rupa.

\section{b. Winding ( Belitan )}

Belitan terdiri dari batang tembaga berisolasi yang mengelilingi inti besi, dimana saat arus bolak balik mengalir pada belitan tembaga tersebut, inti besi akan terinduksi dan menimbulkan flux magnetic.

\section{c. Bushing}

Bushing merupakan sarana penghubung antara belitan dengan jaringan luar. Bushing terdiri dari sebuah konduktor yang diselubungi oleh isolator. Isolator tersebut berfungsi sebagai penyekat antara konduktor bushing dengan body main tank transformator

\section{d. Pendingin}

Salah satu Penyebab utama munculnya kegagalan pada transformator adalah adanya panas berlebih. Panas berlebih biasanya ditimbulkan oleh berbagai faktor seperti pembebanan berlebih, rugi histeris, arus eddy, adanya proses oksidasi yang menghasilkan karat, air, dan lain-lain. Oleh karena itu transformator memerlukan sistem pendingin untuk mengontrol panas yang timbil. Panas yang berlebih akan memacu reaksi berantai yang akan mempercepat penurunan usia dan kualitas kerja sistem isolasi baik pada minyak isolator maupun isolator kertas.

\section{e. Oil preservation \& expansion (Konservator)}

Saat terjadi kenaikan suhu operasi pada transformator, minyak isolasi akan memuai sehingga volumenya bertambah. Sebaliknya saat terjadi penurunan suhu operasi, maka minyak akan menyusut dan volume minyak akan turun. Konservator digunakan untuk menampung minyak pada saat transformator mengalamui kenaikan suhu.

\section{f. Dielectric (Minyak isolasi transformator \& Isolasi kertas )}

Minyak isolasi pada transformator berfungsi sebagai media isolasi, pendingin dan pelindung belitan dari oksidasi. Sedangkan Isolasi kertas berfungsi sebagai isolasi, pemberi jarak, dan memiliki kemampuan mekanis.

\section{g. Tap Changer}

Kestabilan tegangan dalam suatu jaringan merupakan salah satu hal yang dinilai sebagai kualitas tegangan. Transformator dituntut memiliki nilai tegangan output yang stabil sedangkan besarnya tegangan input tidak selalu sama. Dengan mengubah banyaknya belitan pada sisi primer diharapkan dapat merubah ratio antara belitan primer dan sekunder dan dengan demikian tegangan output/sekunder pun dapat disesuaikan dengan kebutuhan sistem berapapun tegangan input/primernya. 
Penyesuaian ratio belitan ini disebut Tap changer.

\subsection{Pemeliharaan Transformator Tenaga.}

Pemeliharaan peralatan listrik tegangan tinggi adalah serangkaian tindakan atau proses kegiatan untuk mempertahankan kondisi dan meyakinkan bahwa peralatan dapat berfungsi sebagaimana mestinya sehingga dapat dicegah terjadinya gangguan yang menyebabkan kerusakan.

\subsubsection{Jenis-jenis Pemeliharaan Transformator Tenaga.}

\section{a. . In Service Inspection}

adalah kegiatan inspeksi yang dilakukan pada saat transformator dalam kondisi bertegangan / operasi, dengan tujuancuntuk mendeteksi secara dini ketidaknormalan yang mungkin terjadi didalam trafo tanpa melakukan pemadaman

\section{b. In Service Measurement}

adalah kegiatan pengukuran / pengujian yang dilakukan pada saat transformator sedang dalam keadaan bertegangan / operasi, dengan untuk mengetahui kondisi trafo lebih dalam tanpa melakukan pemadaman.

\section{c. Shutdown testing / measurement}

Adalah pekerjaan pengujian yang dilakukan pada saat transformator dalam keadaan padam. Pekerjaan ini dilakukan pada saat pemeliharaan rutin maupun pada saat investigasi.

\subsection{FMEA (Failure mode and Effect Analysis)}

FMEA (Failure Mode and Effect Analysis) adalah suatu metode untuk menganalisa penyebab kegagalan pada suatu peralatan (Pamudji 2014:17). FMEA merupakan pendekatan sistematik yang menerapkan suatu metode pentabelan untuk membantu proses pemikiran yang digunakan oleh engineers untuk mengidentifikasi mode kegagalan potensial dan efeknya dengan cara membagi suatu sistem menjadi beberapa subsistem yang kemudian diikuti dengan penentuan jenis gejala yang dapat diamati[8] .

\subsection{Norm atau Batasan}

adalah referensi nilai yang dipakai untuk memilahmilah apakah item dalam kondisi baik, moderat atau buruk. Norm dibuat dengan mempertimbangkan berbagai sumber, yaitu: Standar internasional, misalnya: IEEE, IEC, ANSI, CIGRÉ dan Standar nasional, misalnya: SPLN.

\subsection{FMEA Transformator Tenaga}

Hal utama yang dilakukan pada tahapan penyusunan FMEA Transformator Teenaga adalah penentuan sub system:

a. Sub sistem Bushing

b. Sub sistem Dielektrik (isolasi minyak \& kertas)

c. Sub sistem EMC(Electromagnetic Circuit) \& CCU(Current Carying Unit)

d. Sub sistem OLTC ( On Load Tap Changer)

e. Sub sistem Pendingin

f. Sistem Pernafasan

g. Subsistem Struktur mekanik

\subsection{Penilaian Kondisi Transformer (Scoring).}

Penilaian Kondisi merupakan suatu metode penilaian terhadap suatu obyek yang berdasarkan pada kondisi fisik dan fungsi obyek yang diamati. Penilaian kondisi berhubungan erat dengan Condition Based Maintenance, dimana obyek yang diamati kondisinya ini kemudian ditentukan tingkat unjuk kerjanya lalu kemudian diamati diberikan maintenace berdasarkan kondisinya tersebut. Secara umum penilaian kondisi memberikan sebuah penilaian kondisi atas fenomena-fenomena yang terjadi dan berpengaruh pada parameter yang terukur pada obyek.

Didalam Penilaian Kondisi terdapat 2 aspek yang terlibat yaitu risk assessment dan monitoring diagnosis. Risk assessment disini berarti penilaian terhadap kemungkinan-kemungkinan resiko yang bisa terjadi pada obyek tersebut. Dalam risk assessment ini kita menentukan kemungkinankemungkinan resiko yang terjadi pada obyek serta penyebabnya.

Aspek lain yang penting dalam penilaian kondisi adalah monitoring diagnosis. 
Monitoring diagnosis berarti melakukan suatu pemantauan terhadap parameter-parameter yang berpengaruh pada suatu obyek dan kemudian menentukan fenomena apa yang terjadi. Berikut adalah hubungan antara condition assessment, risk assessment, dan monitoring diagnosis (Gambar 3).

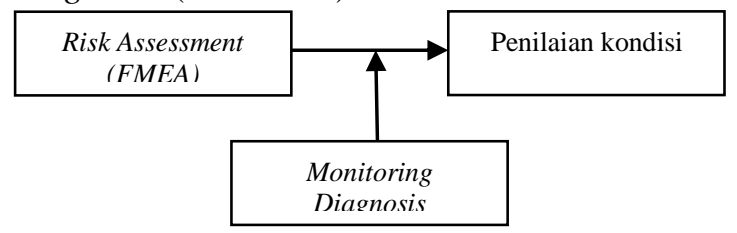

Gambar 3 Bagan hubungan scoring

Dalam menghitung nilai scoring, nilai setiap parameter dicari berdasarkan batas standar internasional yang dipakai dan rumus. Setiap nilai parameter yang telah didapat kemudian dijumlahkan semua untuk mendapat nilai akhir scoring. Scoring trafo dapat bersifat kualitatif maupun kuantitatif dengan jumlah klasifikasi yang bergantung pada kemampuan kita untuk menentukan batasan klas. Indeks kondisi ini digunakan sejak asesmen tingkat awal hingga asesmen tingkat lanjut. Karena itu yang kita pakai adalah indeks kondisi yang bersifat kuantitatif(Gambar4).

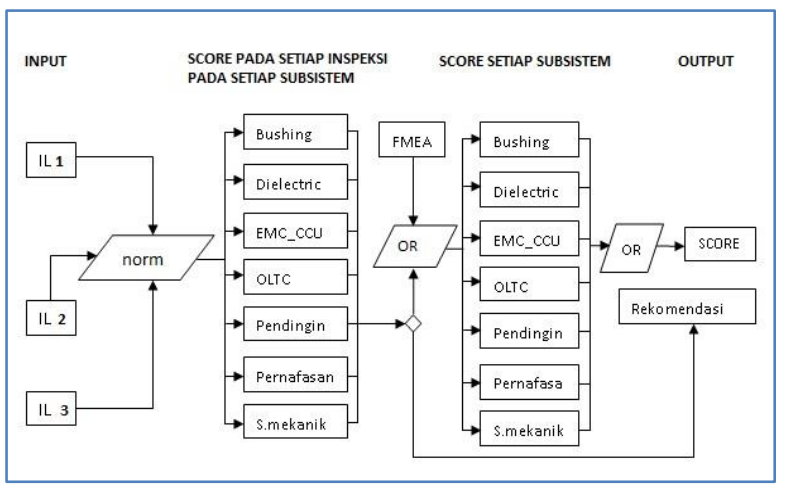

Gambar 4. Konsep umum scoring

Input merupakan data yang diambil dari hasil inspeksi yaitu Inspeksi Level 1, Level 2, dan Level 3.

Batasan (Norm) hasil pengujian.

Norm yang ditentukan oleh standard, guide dan panduan pabrikan umumnya hanya membedakan 2 (dua) kondisi item, yaitu: baik atau buruk, serta dibuat berdasarkan kondisi lingkungan (iklim dan jaringan kelistrikan) yang berbeda dengan Indonesia. Sementara kita menganut sistem 3 (tiga) kategori kondisi yaitu Baik, Sedang, Buruk. Oleh karena itu, norm yang layak dipakai seharusnyalah yang juga diturunkan dari pengalaman lapangan dan informasi aging pada kondisi lingkungan di PLN.

Maka dalam perhitungan atau scooring ini dibagi menjadi 3 (tiga) klas dengan kode indeks kondisi sebagai berikut:

- klas baik : kode indeks kondisi 9

- klas moderat : kode indeks kondisi 6

- klas buruk : kode indeks kondisi 1

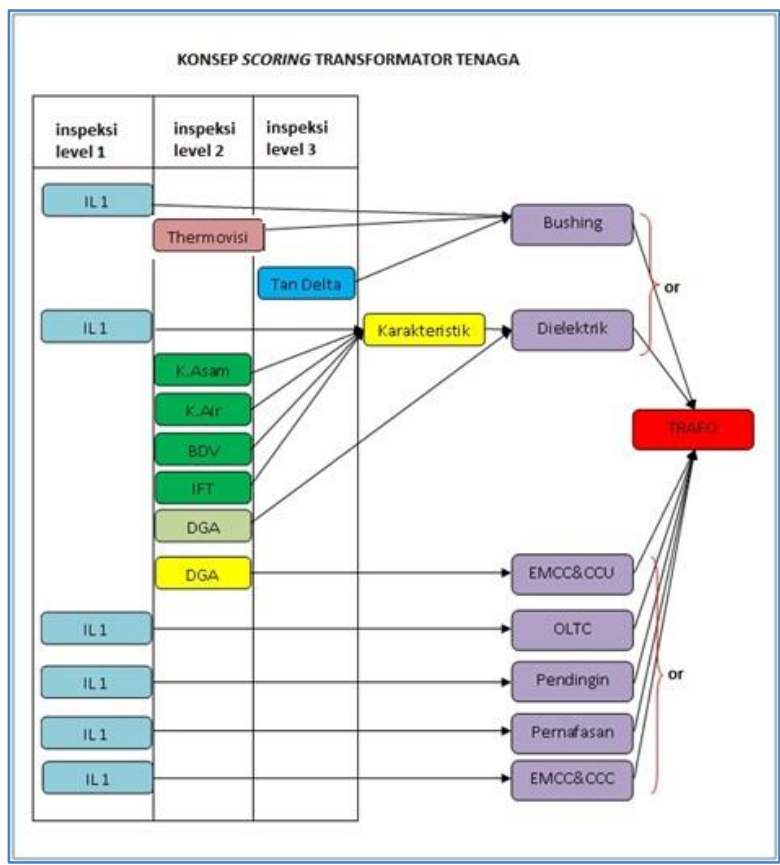

Gambar 5 Konsep detail scoring

\section{HASIL SCORING}

\subsection{Hasil scoring pada subsistem Bushing}

Norm yang digunakan:

1. inspeksi Level 1: sesuai kondisi visual

2. Inspeksi Level 2 (Thermovision)

Tabel 1. Standart Thermovisi berdasarkan SPLN.

\begin{tabular}{|c|c|c|}
\hline Kategori & $|\mathbf{A} \mathbf{T}| \mathbf{m a x}$ & keterangan \\
\hline 9 & $<20$ & Normal \\
\hline 6 & $21-40$ & Pengukuran Ulang \\
\hline 1 & $>41$ & Perbaikan \\
\hline
\end{tabular}


3. Inspeksi Level 3( Tangen Delta).

Tabel 2. Standart Tangen Delta berdasarkan SPLN.

\begin{tabular}{|c|c|c|c|c|}
\hline Test & Method & $\mathbf{9}$ & $\mathbf{6}$ & $\mathbf{1}$ \\
\hline Tan Delta & $\mathrm{C} 1$ & $<0,5 \%$ & $0,5-0,7 \%$ & $>1 \%$ \\
\hline
\end{tabular}

Hasil Scoring Subsistem Bushing:

Tabel 3. Hasil Scoring Subsistem Bushing.

\begin{tabular}{|c|c|c|c|c|c|c|c|c|c|c|c|c|c|c|c|c|c|}
\hline \multirow{3}{*}{$\mathrm{T} / \mathbf{R} \mathbf{B A Y}$} & \multirow{3}{*}{$\underset{\text { BUSHING }}{\text { HI }}$} & \multicolumn{8}{|c|}{ II/2 } & \multicolumn{7}{|c|}{ II3 } & \multirow{3}{*}{$\begin{array}{l}\text { SCORR } \\
\text { BLSHINC }\end{array}$} \\
\hline & & \multicolumn{4}{|c|}{$\begin{array}{l}\text { THFRMOO } \\
\text { BLSHING } \\
\text { FRIMIRK }\end{array}$} & \multicolumn{4}{|c|}{$\begin{array}{l}\text { THERMDO } \\
\text { BUSHING } \\
\text { SE KUNDER R }\end{array}$} & \multicolumn{4}{|c|}{$\begin{array}{l}\text { TD } \\
\text { BUSHING } \\
\text { PRIMIEK }\end{array}$} & \multicolumn{3}{|c|}{$\begin{array}{c}\text { TD } \\
\text { BUSHING } \\
\text { SEKUNDER }\end{array}$} & \\
\hline & & $\mathrm{R}$ & $s$ & $\mathrm{~T}$ & $\mathrm{~N}$ & R & $\mathrm{s}$ & $\mathrm{T}$ & 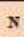 & R & $s$ & $\mathrm{~T}$ & $\mathrm{~s}$ & $\mathrm{~K}$ & 3 & T N & \\
\hline $\begin{array}{c}\text { IR } F=1 \\
15070 \mathrm{KV}\end{array}$ & 8,75 & 6 & 6 & 6 & 6 & 6 & 6 & 6 & 6 & 1 & 1 & 1 & 6 & 1 & 1 & & 4,40 \\
\hline $\begin{array}{c}\text { TRF } F=2 \\
15020 \mathrm{KV}\end{array}$ & 9 & 9 & 9 & 9 & 9 & 9 & 9 & 9 & 9 & 9 & 9 & 9 & 9 & 9 & 9 & 99 & 9 \\
\hline $\begin{array}{c}\text { IR:F }=3 \\
15020 \mathrm{KV}\end{array}$ & 8,47 & 6 & 6 & 6 & 6 & 6 & 6 & 6 & 6 & 1 & 1 & 1 & 1 & 1 & 1 & 66 & 4,38 \\
\hline
\end{tabular}

\subsection{Hasil scoring pada subsistem Dielectric}

Norm yang digunakan:

1. inspeksi Level 1: sesuai kondisi visual

2. Inspeksi Level 3

a.Pengujian Kadar air

Tabel 4. standart pengujian kadar air

\begin{tabular}{|c|c|c|c|}
\hline Tegangan & Bagus & Cukup & Buruk \\
\hline $500 \mathrm{kV}$ & $<5$ & $5-10$ & $>10$ \\
$150 \mathrm{kV}$ & $<5$ & $5-15$ & $>15$ \\
$70 \mathrm{kV}$ & $<10$ & $5-25$ & $>25$ \\
\hline
\end{tabular}

b .Pengujian suhu minyak

Tabel 5. standart pengujian suhu minyak

\begin{tabular}{|c|c|c||}
\hline Kategori & Suhu Minyak & Keterangan \\
\hline 9 & $<70$ & Baik \\
\hline 6 & $71-99$ & Sedang \\
\hline 1 & $>100$ & Jelek,Berbahaya \\
\hline
\end{tabular}

c .Pengujian interfacial Tension (IFT):

Tabel 6. standart pengujian interfacial Tension

\begin{tabular}{|c|c|c|}
\hline Kategori & Kadar asam & IFT \\
\hline 9 & $<0,05$ & $20-43$ \\
\hline 6 & $0,051-0,1$ & $17-34$ \\
\hline 1 & $>0,11$ & $15-27$ \\
\hline
\end{tabular}

d .Pengujian Tegangan Tembus:

Tabel 7. standart pengujian tegangan tembus.

\begin{tabular}{|r|c|c|c|}
\hline Tegangan & Bagus & Cukup & Buruk \\
\hline $500 \mathrm{kV}$ & $>60$ & $50-60$ & $<50$ \\
$150 \mathrm{kV}$ & $>50$ & $40-50$ & $<40$ \\
$70 \mathrm{kV}$ & $>40$ & $30-40$ & $<30$ \\
\hline
\end{tabular}

Hasil Scoring Subsistem Dielektrik:

Tabel 8. Hasil Scoring Subsistem Dielektrik.

\begin{tabular}{|c|c|c|c|c|c|c|c|}
\hline TR BAY & $\begin{array}{c}\text { III } \\
\text { DILLEKRIK }\end{array}$ & $\begin{array}{c}\text { KADAR } \\
\text { AIR }\end{array}$ & $\begin{array}{l}\text { SUHU } \\
\text { MINYAK }\end{array}$ & $\begin{array}{l}\text { KADAR } \\
\text { ASAM }\end{array}$ & BDV & IF $\mathrm{T}$ & $\begin{array}{c}\text { SCORE } \\
\text { DIELEKTRIK }\end{array}$ \\
\hline $\begin{array}{l}\text { TRFः1 } \\
15070 \mathrm{KV}\end{array}$ & 7.16667 & 1 & 6 & 1 & 1 & 6 & 4.8 \\
\hline $\begin{array}{l}\mathrm{TRF}=2 \\
15020 \mathrm{KV}\end{array}$ & 9 & 9 & 9 & 9 & 9 & 9 & 7.9 \\
\hline $\begin{array}{l}\text { TRF } \approx 3 \\
15020 \mathrm{KV} \\
\end{array}$ & 6.16667 & 1 & 6 & 1 & 1 & 1 & 3,3 \\
\hline
\end{tabular}

\subsection{Hasil scoring pada subsistem EMC \& CCU}

Norm yang digunakan adalah Inspeksi Level 3:

a. Pengujian DGA(Dissolved Gas Analysis)

Tabel 9. standart pengujian DGA

\begin{tabular}{|c|c|c|c|c|c|c|c|c|}
\hline \multirow[b]{2}{*}{ Status } & \multicolumn{8}{|c|}{ Batas honsentrasi key gas terlarut (dissohed key gas) [uL/L (ppm)] } \\
\hline & $\begin{array}{c}\text { Hidrogen } \\
\left(\mathrm{H}_{2}\right)\end{array}$ & $\begin{array}{l}\text { Metana } \\
\left(\mathrm{CH}_{4}\right)\end{array}$ & $\begin{array}{l}\text { tsetilen } \\
\left(\mathrm{C}_{2} \mathrm{H}\right)\end{array}$ & $\begin{array}{l}\text { Etilen } \\
\left(\mathrm{C}_{2} \mathrm{H}_{4}\right)\end{array}$ & $\begin{array}{l}\text { Etane } \\
\left(\mathrm{C}_{2} \mathrm{H}_{6}\right)\end{array}$ & $\begin{array}{c}\text { Kartoun } \\
\text { mowokida/(CO) }\end{array}$ & $\begin{array}{l}\text { Karbon } \\
\text { dioksida(CO2) }\end{array}$ & IDCG \\
\hline Baik & $<100$ & $<120$ & $<1$ & $<50$ & 465 & $<50$ & 8500 & 820 \\
\hline Sedang & $101-700$ & 121400 & 2.9 & $51-100$ & $66-100$ & $351-570$ & $2500-4000$ & $721-1920$ \\
\hline Buruk & $>701$ & $>401$ & $>10$ & $>101$ & $>101$ & $>571$ & $\times 4001$ & $>1921$ \\
\hline
\end{tabular}

b. Pengujian Tahanan Isolasi(Indeks Polarisasi) Tabel 10. standart pengujian Indeks Polarisasi.

\begin{tabular}{|c|c|c|}
\hline Kategori & IP & Keterangan \\
\hline 9 & $>1,26$ & Baik \\
\hline 6 & $1,0-1,25$ & Sedang \\
\hline 1 & $<1,0$ & Jelek, Berbahaya \\
\hline
\end{tabular}

Hasil Scoring Subsistem EMC \& CCU:

Tabel 11. Hasil Scoring Subsistem EMC \& CCU

\begin{tabular}{|c|c|c|c|c|c|c|c|c|c|c|c|}
\hline TR BAY & H2 & CH4 & co & $\mathrm{CO} 2$ & $\mathrm{C} 2 \mathrm{H} 4$ & $\mathrm{CH}$ & $\mathrm{C} \mathrm{CH}_{2}$ & TDCG & $\begin{array}{l}\text { TAHANAN } \\
\text { ISOL.ASI }\end{array}$ & $\mathbb{P}$ & $\begin{array}{l}\text { SCORE } \\
\text { EMCCCU }\end{array}$ \\
\hline $\begin{array}{l}\mathrm{TRF}=1 \\
15070 \mathrm{KV}\end{array}$ & 6 & 6 & 1 & 6 & 6 & 6 & 1 & 1 & 9 & 6 & 4.8 \\
\hline $\begin{array}{l}\mathrm{TRF}=2 \\
150202 \mathrm{KV}\end{array}$ & 9 & 9 & 1 & 9 & 9 & 9 & 9 & 6 & 9 & 6 & 7.9 \\
\hline $\begin{array}{l}\text { TRF:3 } \\
15020 \mathrm{KV}\end{array}$ & 6 & 1 & 1 & 1 & 6 & 1 & 1 & 1 & 9 & 6 & 3,3 \\
\hline
\end{tabular}




\subsection{Hasil scoring pada subsistem OLTC}

Norm yang digunakan:

1. inspeksi Level 1: sesuai kondisi visual

2. Inspeksi Level 3 (Ratio Belitan)

Tabel 12. standart pengujian Ratio Belitan

\begin{tabular}{|c|c|c|}
\hline Kategori & Ratio & Keterangan \\
9 & $<0,49$ & Baik \\
6 & $0,5-0,99 \%$ & Sedang \\
1 & $>1 \%$ & Jelek, Berbahaya \\
\hline
\end{tabular}

Hasil Scoring Subsistem OLTC:

Tabel 13. Hasil Scoring Subsistem OLTC

\begin{tabular}{|c|c|c|c|c|c|c|c|c|c|}
\hline \multirow[b]{2}{*}{ T/R Bay } & \multirow[b]{2}{*}{ Merk } & \multirow[b]{2}{*}{ Type } & \multirow[b]{2}{*}{ Serial Id } & \multirow[b]{2}{*}{ Buatan } & \multirow{2}{*}{$\begin{array}{l}\text { Tahun } \\
\text { Buat }\end{array}$} & \multirow[b]{2}{*}{ Operasi } & \multicolumn{3}{|c|}{ OLTC } \\
\hline & & & & & & & III & RATIO & SCORE \\
\hline $\begin{array}{l}\text { TRF=1 } \\
15070 \mathrm{KV}\end{array}$ & ALSTHOM & 97 & 21731101 & FRANCE & 1976 & 01.01197 & 7.5 & 1 & 4.25 \\
\hline $\begin{array}{l}\text { TRF }=2 \\
150: 20 \mathrm{KV}\end{array}$ & PAUWELS & 22 & $\begin{array}{l}\mathrm{H} 66880 \\
02\end{array}$ & FRANCE & 2011 & 02052011 & 9 & 9 & 9 \\
\hline $\begin{array}{l}\text { TRF }=3 \\
15020 \mathrm{KV} V\end{array}$ & PASTI & 9 & 934.0006 & INDONESIA & 1993 & 01.011993 & 6.25 & 1 & 3.025 \\
\hline
\end{tabular}

\subsection{Hasil scoring pada subsistem Pendingin}

Norm yang digunakan:

1. inspeksi Level 1: sesuai kondisi visual Hasil Scoring Subsistem Pendingin:

Tabel 14. Hasil Scoring Subsistem Pendingin.

\begin{tabular}{|c|c|c|c|c|c|c|c|}
\hline T/R Bay & Merk & Type & SerialId & Buat an & $\begin{array}{c}\text { Tahun } \\
\text { Buat }\end{array}$ & Operasi & $\begin{array}{c}\text { SCORE } \\
\text { PENDINGIN }\end{array}$ \\
\hline $\begin{array}{c}\mathrm{TRF}=1 \\
150 \cap \mathbb{K} \mathrm{KV}\end{array}$ & ALSTHOM & 97 & 21731101 & FRANCE & 1976 & $0101 / 1977$ & 9 \\
\hline $\begin{array}{c}\text { TRF }=2 \\
150: 20 \mathrm{KV}\end{array}$ & PATTWELS & 22 & $\mathrm{H} 66880 \mathrm{C2}$ & FRANCE & 2011 & $0205 / 2011$ & 9 \\
\hline $\begin{array}{c}\mathrm{TRF}=3 \\
150,20 \mathrm{KV}\end{array}$ & PASTI & 9 & 934.0606 & INDONESIA & 1993 & $0101 / 1993$ & 7.5 \\
\hline
\end{tabular}

\subsection{Hasil scoring pada subsistem Pernafasan}

Norm yang digunakan:

1. inspeksi Level 1: sesuai kondisi visual

Hasil Scoring Subsistem Pernafasan:

Tabel 15. Hasil Scoring Subsistem.

\begin{tabular}{|c|c|c|c|c|c|c|c||}
\hline TRR Bay & Merk & Type & Serial Id & Buatan & $\begin{array}{c}\text { Tahun } \\
\text { Buat }\end{array}$ & Operasi & $\begin{array}{c}\text { SCORE } \\
\text { PERNAFASAN }\end{array}$ \\
$\begin{array}{c}\text { TRF:1 } \\
15070 \mathrm{KV}\end{array}$ & ALSTHOM & 97 & 21731101 & FRANCE & 1976 & 01011977 & 7.5 \\
\hline $\begin{array}{c}\text { TRFF: } \\
15020 \mathrm{KV}\end{array}$ & PAITWELS & 22 & H 6688002 & FRANCE & 2011 & 02052011 & 9 \\
\hline $\begin{array}{c}\text { TRFF3 } \\
15020 \mathrm{KV}\end{array}$ & PASTI & 9 & 934.0006 & NNDONESIA & 1993 & 01011993 & 6 \\
\hline \hline
\end{tabular}

\subsection{Hasil scoring pada subsistem S.Mekanik}

Norm yang digunakan:

1. inspeksi Level 1: sesuai kondisi visual Hasil Scoring Subsistem S. Mekanik:
Tabel 16. Hasil Scoring Subsistem S.Mekanik.

\begin{tabular}{|c|c|c|c|c|c|c|c|}
\hline T/R Bay & Merk & Type & Serial Id & Buat an & $\begin{array}{c}\text { Tahun } \\
\text { Buat }\end{array}$ & Operasi & $\begin{array}{c}\text { SCORE } \\
\text { SMEKANIK }\end{array}$ \\
\hline $\begin{array}{c}\text { TRF }=1 \\
150 \cap 0 \mathrm{KV}\end{array}$ & ALSTHOM & 97 & 21731101 & FRANCE & 1976 & $0101 / 1977$ & 7.5 \\
\hline $\begin{array}{c}\mathrm{TRF}=2 \\
150.20 \mathrm{KV}\end{array}$ & PAUTWELS & 22 & H $66880 \mathrm{OC}$ & FRANCE & 2011 & $0205 / 2011$ & 9 \\
\hline $\begin{array}{c}\mathrm{TRF}=3 \\
15022 \mathrm{KVV}\end{array}$ & PASTI & 9 & 934.0606 & INDONESIA & 1993 & $01 / 01 / 1993$ & 6 \\
\hline
\end{tabular}

\subsection{Hasil scoring total}

Tabel 17. Hasil Scoring total.

\begin{tabular}{|c|c|c|c|c|c|c|c|c|}
\hline TREAY & BUSHING & DIF LEKTRIK & EMCOCO & OLTC & FENDENCEN & PERNAFASAN & S.MERANSA & SCORE TOTAI \\
\hline $\begin{array}{c}\mathrm{TRF}=1 \\
150 / 70 \mathrm{KV}\end{array}$ & 4,40 & 3,69 & 4,8 & 4,25 & 9 & 7,5 & 7,5 & 5,88 \\
\hline $\begin{array}{c}\mathrm{TRF}=2 \\
150 / 20 \mathrm{KV}\end{array}$ & 9 & 9 & 79 & 9 & 9 & 9 & 9 & 8,84 \\
\hline $\begin{array}{c}\text { TRF }=3 \\
150 / 20 \mathrm{KV}\end{array}$ & 4,38 & 2,69 & 3,3 & 3,625 & 7,5 & 6 & 6 & 4,78 \\
\hline
\end{tabular}

\section{PENUTUP}

\subsection{Kesimpulan}

a. b. Dari analisa kondisi didapatkan hasil scoring yaitu:

\section{Trafo $1=\mathbf{5 , 8 8}$}

Dari hasil analisa rendahnya hasil scoring trafo 1 disebabkan beberapa hal, yaitu:

- Kebocoran bushing primer phase $\mathrm{S}$

- Hasil thermo bushing menunjukan panas.

- Hasil Uji Tan Delta pada Bushing > $1 \%$.

- Kondisi silicagel maintank berwarna putih

- Hasil Uji Kadar air, Kadar asam, dan BDV dibawah standart

- Hasil Uji DGA banyak yang dibawah standart

- Hasil uji ratio dibawah standart.

- Ada rembesan pada maint tank.

\section{Trafo $2=8,73$}

Untuk trafo 2 tidak ada banyak failure, hanya perlu perbaikan-perbaikan kecil untuk meningkatkan hasil scoringnya seperti hasil TDCG (Total Dissolved Combustible Gas) sudah berada dikategori sedang, peru dilakukan fiter minyak isolasi agar hasil uji TDCG kembali normal.

\section{Trafo $3=4,83$}

Dari hasil analisa rendahnya hasil scoring trafo 3 disebabkan beberapa hal, yaitu: 
- Kebocoran bushing primer phase T

- Hasil thermo kondisi sedang

- Hasil Uji Tan Delta pada Bushing > 1\%

- Kondisi silicagel maintank berwarna putih

- Hasil Uji Kadar air, Kadar asam, dan BDV dibawah standart

- Hasil Uji DGA banyak yang dibawah standart

- Kondisi silica gel OLTC berwana putih.

- Hasil uji ratio dibawah standart

- Rembesan pada maint tank

- Motor kipas pendingin ada yang mati

Agar nilai scoring bisa naik, subsistemsubsistem yang mengalami penurunan nilai, agar secepatnya dilakukan perbaikan sesuai rekomendasi sebelum failure bertambah besar dan memperburuk kondisi transformator tenaga.

c. Secara umum kondisi Transformator Tenaga di GI Segoromadu menurut analisa hasil Inspeksi Level 1,Level 2, maupun Level 3, telah mengalami penurunan kondisi terutama pada Trafo 1 dan Trafo 3.

d. Diagnosa kondisi transformator dengan menggunakan metoda scoring trafo ini bisa diketahui kondisi transformator secara menyeluruh terhadap kondisi kesehatan transformator tenaga berdasarkan dari berbagai hasil pengujian dan kriteria kondisi yang terkait dengan faktor-faktor degradasi jangka panjang yang secara kumulatif berpengaruh pada masa hidup operasi transformator.

e. Dengan melihat kondisi inspeksi visual, online measurement, off-line measurement serta pengujian proteksi maka perlu disusun suatu kajian resiko khususnya untuk trafo 1 dan trafo 3 demi menjaga kontuinitas penyaluran energi listrik.

f. Berdasarkan score yang didapat maka disarankan untuk melaksanakan inspeksi lanjutan, baik itu pengujian dengan interval setiap bulan, direct shutdown maupun perencanaan untuk penggantian trafo 1 dan 3 .

\subsection{Saran}

1. Analisa kondisi transformator seperti ini agar bisa diaplikasikan ditempat lain untuk mengetahui kondisi real transformator tenaga dengan cepat dan akurat.

2. Untuk penelitian selanjutnya dalam menentukan indeks kondisi transformator tenaga, bisa ditambahkan historical gangguan transformator tenaga sebagai parameter parameter untuk menentukan scoring transformator tenaga.

\section{DAFTAR PUSTAKA}

1. Ariawan,Putu R. (2009). Kegagalan Bahan Isolasi. Bali : UDAYANA

2. Chumaidy, Adib. (2010). Analisa Kegagalan Minyak Isolasi Pada Transformator Daya Berbasis Kandungan Gas Terlarut. Jakarta: ISTN

3. Faishal, Muhammad. (2007). Analisa Jenis Kegagalan Transformator Tenaga Berdasarkan Hasil Uji DGA Dengan Metode Roger's Ratio PLTU Tambak Lorok. Semarang : UNDIP

4. Halow,James,H. (2004) Electrical Power Transformer Engineering. USA : CRC Press.

5. Hardityo, Rahmat (2008) Deteksi Dan Analisis Indikasi Kegagalan Transformator Dengan Metode Analisis Gas Terlarut. Depok : UI

6. Iskhan, Dahlan, (2010). Buku Petunjuk Batasan Operasi dan Pemeliharaan Peralatan Penyaluran Tenaga Listrik Transformator Tenaga. Jakarta : PT.PLN (Persero)

7. Solikhudin, M. (2013). Studi Penyebab Kegagalan Transformator Tenaga. Depok :UI

8. Pamudji, Nur. (2014). Buku Pedoman Pemeliharaan Transformator Tenaga. Jakarta : PT.PLN (Persero). 